\title{
FINE AND ULTRAFINE PARTICULATE MATTER IN THE WORK ENVIRONMENT AND THEIR POTENTIAL IMPACT ON MENTAL STATE OF WORKERS
}

\author{
${ }^{1}$ Michal URBÁNEK, ${ }^{1}$ Klaudia KÖBÖLOVÁ, ${ }^{1}$ Vladimír ADAMEC, ${ }^{2}$ Kateřina WOLFOVÁ, \\ ${ }^{3}$ Kristina ČABANOVÁ, ${ }^{1}$ Jana Victoria MARTINCOVÁ \\ ${ }^{1}$ Brno University of Technology, Institute of Forensic Engineering, Brno, Czech Republic, EU, \\ michal.urbanek@usi.vutbr.cz \\ ${ }^{2}$ Masaryk University, Faculty of Arts, Brno, Czech Republic, EU \\ ${ }^{3}$ VSB - Technical University of Ostrava, Ostrava, Czech Republic, EU
}

https://doi.org/10.37904/nanocon.2020.3762

\begin{abstract}
This study presents the results of pilot measurement, where the exposure of fine and ultrafine particulate matter was monitored. The measurement was performed in different workplaces, where these particles are produced unintentionally. These were mainly engineering operations of welding shops, paint shops, but laboratory workplace was also observed. The measurement consisted of collecting information and measuring the concentration of particles in the workplace. Data collection was primarily focused on inhalation exposure. Particle samples were also obtained during the measurement to determine the morphology and chemical composition of the particles. An approach was also proposed to observe the selected psychological aspects (e.g. employee well-being) and occupational health and safety in an environment with the presence of fine and ultrafine particles.
\end{abstract}

Keywords: Work environment, fine and ultrafine particles, risk assessment, industrial and organizational psychology

\section{INTRODUCTION}

Fine particles (FP) and ultrafine particles (UFP) as a part of everyday life can have potential unacceptable impact on workers, as they are first to be exposed to the potential risk. It is necessary to set safety and health criteria at work that define the responsible development of nanotechnologies. Schulte et al. [1] presents five critical actions that should make a decisive impact on responsible development: the identification and monitoring of hazardous particles in the workplace, assess exposure and report potential hazards to workers, manage risks to safety and health at work, and support the safe development of nanotechnology.

Three basic group of origin of FP and UFP can be used in relation to work environment [2]:

- $\quad$ processes in which particles/materials are intentionally produced,

- $\quad$ processes related to the use of nanomaterials,

- $\quad$ particles created unintentionally during work processes.

Effects of nanoparticles on human health are currently in place with fast development of technologies. The toxic effect of inhaled nanoparticles has been proven many times in the last years, however, there is still discussion concerning the exact mechanism of this impact on living organisms [3-5].

The toxicity of nanoparticles is affected by many factors. These factors include their physical and chemical properties, size, shape, specific surface area, surface charge, catalytic activity, and the presence or absence of the shell and active groups on the surface [6]. Exposure time and concentration are part of the key indicators 
for setting standards of health assessment risks [7]. Inorganic nanoparticles can enter the body in four main ways: ingestion, inhalation, dermal penetration, blood circulation [8].

Song et al. [9] suggest that there is an association between long-term nanoparticles exposure without protective measures and serious damage to human lungs. Effective and protective methods should be used to in terms of prevention.

Castillo [10] emphasizes that an important factor is the involvement of employees in determining appropriate precautionary measures to eliminate or reduce the possibility of exposure to nanoparticles, where technically possible. Castillo [10] states as an example of good practice an independent government agency (Safe work Australia), which developed a tool to evaluate and identify safe ways of working with nanomaterials for industries. The knowledge of processes and procedures at the workplace is evaluated in the following areas:

- $\quad$ equipment design,

- modification / substitution of nanoparticles,

- closed system works,

- local ventilation,

- $\quad$ high efficiency particulate air filters (HEPA).

In comparison, European legislation states the following hierarchy of measures related to exposure to nanomaterials in the workplace [11]:

- technical control measures at the source,

- $\quad$ organizational measures,

- $\quad$ personal protection equipment, as the last resort.

In addition, there is a lack of legislative regulations on nanosafety [12]. For this reason, a relative comparison of background concentration values and actual measured values is used. In this paper the background value of the concentrations then corresponds to the minimum measured value. This was measured before the shift before processes at workplaces were initiated. The highest concentrations of nanoparticles are usually recorded in facilities where metals are treated under very high temperatures such as iron and steel works or welding shops [13,14].

There is evidence that an individual's experience in the physical, emotional, mental or social sphere affects a person in and out of the workplace [15]. In this regard workplace well-being is considered to be related to all aspects of working life, including how workers feel about their work, work environment and climate, work organization and quality and safety of the physical environment. Measures should be adjusted to complement the occupational health and safety to ensure that workers are safe, healthy, satisfied and engaged at work [16].

In the present work, the exposure to the particles in multiple workplaces with different conditions was estimated. Several measurement metrics were used to determine exposure e.g., concentration, size distribution, morphology, elemental analysis and saliva analysis. This study presents basic approach for measuring exposure in workplaces.

\section{MATERIALS AND METHODS}

For monitoring nanoparticles in atmosphere of the working environment were selected working processes, where these particles are created unintentionally. Multiple workplaces were monitored, these were mainly welding shops, paint shops and laboratory. Tungsten Inert Gas (TIG) and Metal Active Gas (MAG) welding methods were used in welding shops as well as grinding and cleaning with compressed air. In paint shops multilayer painting of stainless steel with sealing was used. Atomic absorption spectroscopy with multiple elements was used in laboratory. The selection of these workplaces is based on workplace measurements 
review [13], where highest concentration of FP and UFP can be observed. The working environment of the laboratory was chosen due to the process of atomization of heavy metals.

Four mobile devices were used in this study to measure concentrations of fine and ultrafine particles in the air, namely Condensation Particle Counter (TSI CPC 3007), TSI AM520 SidePak, Optical Particle Sampler (TSI OPS 3330), AirChek Touch (SKC, Inc.). CPC operates on the principle of particle condensation counting, which allows high measurement accuracy over the particle size range of 0.01-1 $\mu \mathrm{m}$. SidePak is a personal air aerosol meter. It uses photometry to determine the mass concentration of particles in the atmosphere. The basic instrument range is $0.1-10 \mu \mathrm{m}$. The OPS works on a principle of optical spectrometry, it measures not only the concentration but also the number of particles in 16 channels of fractions. The total range of this instrument is $0.3-10 \mu \mathrm{m}$. The Airchek Touch does not belong to the measuring instruments category, but to the sampling devices. It is a sampling pump with adjustable air flow, which is connected to the sampling cassette. A round-shaped polycarbonate filter with porosity of $0.4 \mu \mathrm{m}$ was placed in the cassette. The total particle size range that can be captured by the instrument is $0.01-10 \mu \mathrm{m}$. Thanks to the overlap of the fraction range it is possible to compare the results from individual instruments with each other.

At each workplace, the devices were placed close to the working area and possible source of UFP. It was about 1.5 meters from the work area to avoid damaging the devices and at the same time not to restrict the activities of the worker. One of the AirChek was placed in same area as other devices, second one was attached to the worker clothes. Cassette was placed in breathing zone of worker. Worker's saliva was collected into autoclavable centrifuge microtubes Eppendorf-type $(5 \mathrm{ml})$ before and after work shift. At the beginning of the work shift, workers filled out a simple questionnaire that will be used to create a comprehensive test battery.

Collected filter samples were analysed by scanning electron microscope (SEM MIRA3, Tescan) with using of elemental analysis energy dispersive X-ray analysis (EDAX). Samples of workers saliva (1 ml) were applied in three coats to a slide. Each layer was dried in flowbox under germicidal radiation. Prepared samples were sprayed using an SC7620 sprayer and covered with a thin layer of metal. Subsequently, they were analysed by SEM (Quanta FEG 450, FEI), with EDAX to determine morphology and elemental particle analysis.

\section{RESULTS AND DISCUSION}

The measured data from the CPC, OPS and SidePak show the same trends of obtained results. Data values for comparison from CPC measurement are listed in Table 1. As expected, the lowest values of average concentrations were measured in the laboratory, on the contrary the highest values of concentrations could be observed in welding shops.

Table 1 Comparison of concentrations according to the working environment

\begin{tabular}{|c|c|c|c|}
\hline $\begin{array}{c}\text { Particles concentration } \\
\left(\# / \mathbf{c m}^{\mathbf{3}} \text { ) }\right.\end{array}$ & Welding shops & Paint shops & Laboratory (AAS) \\
\hline Minimum & 32,061 & 1,189 & 1,013 \\
\hline Maximum & 551,582 & 24,199 & 2,091 \\
\hline Mean & 119,981 & 5,219 & 1,530 \\
\hline
\end{tabular}

Minimum values in welding shops were measured before the work shift, maximum values appeared during the cleaning of the weld with compressed air, when the particles were agitated. Other peaks were caused by grinding or welding itself. An example of the concentration course with description is shown in Figure 1. The values in some time periods exceed the maximum value of the measurable concentration by the instrument more than five times. The accuracy of above-limit measurements is reduced, so significantly high values can be taken as random measurement errors. The concentration measured in paint shops is significantly lower due to strong ventilation of entire space. The maximum value was shown when the worker sanded the sealant 
before the ventilation was turned on. Despite the fact that heavy metals (arsenic, cadmium) were atomized in the laboratory, the concentration values were around 1500 particles $/ \mathrm{cm}^{3}$, due to local suction directly above the atomization cuvette.

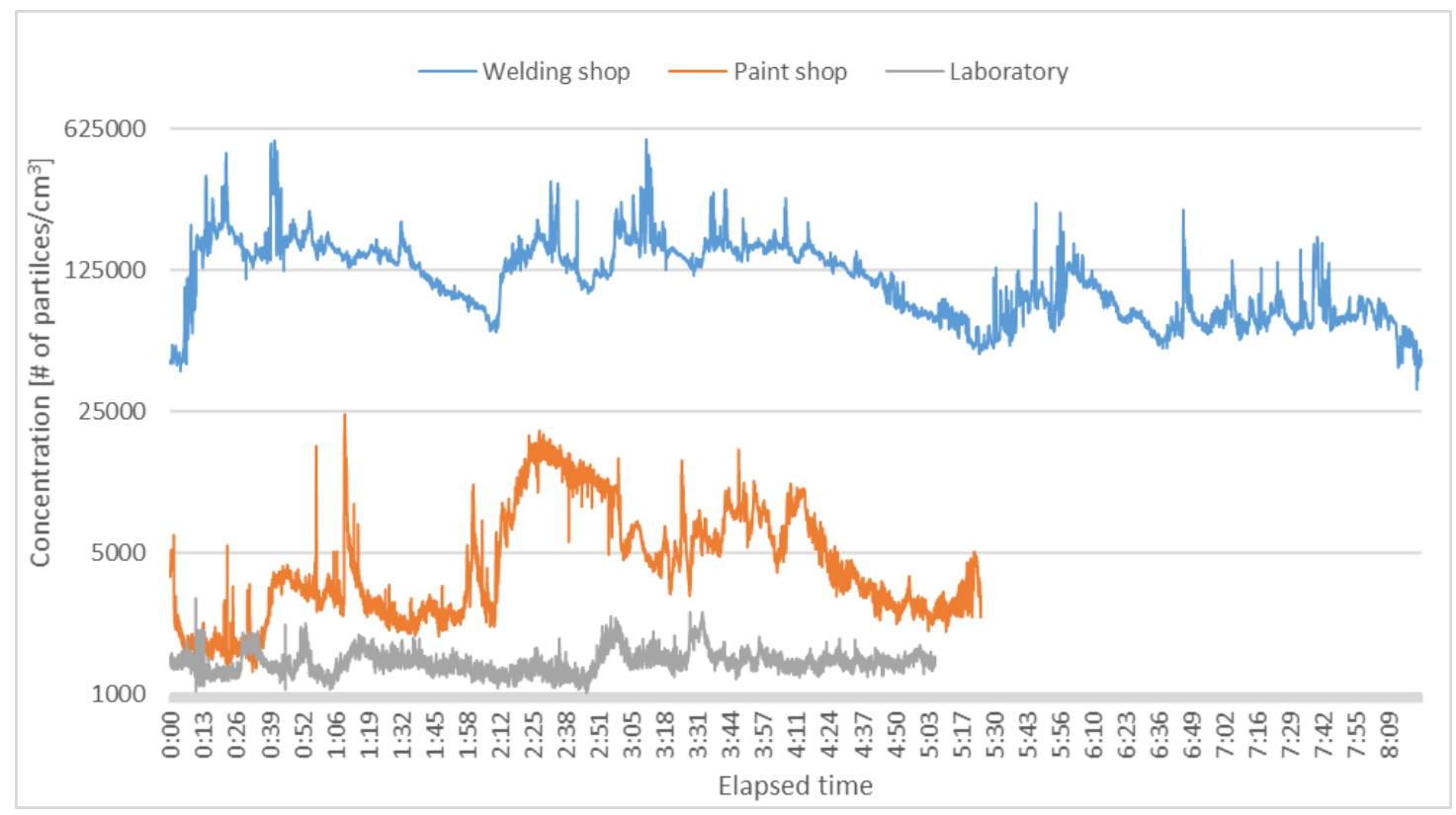

Figure 1 Example of fine and ultrafine concentration courses during the work shift measured with TSI CPC 3007 in different workplaces

From the results of OPS measurements performed at the workplace it can be concluded that particles larger than $0.8 \mu \mathrm{m}$ are formed only in a minimal amount. The highest concentrations were measured for particles 0.3 $\mu \mathrm{m}$ and smaller, which are due to their size able to penetrate through the respiratory system deep into the human organism, where they may have an adverse effect on the worker's health [17].

The results of analyses of saliva and exposed filters of the worker by SEM methods showed the occurrence of elements that were used in the processes. In welding, it was mostly iron, silicon and manganese. Organic elements appeared in the paint shop. Heavy metal elements and relatively larger amounts of radon were captured in the laboratory. The presence of radon in laboratories could be caused by other laboratory devices using this element. In terms of particle morphology, the shape is mostly irregular, flat with sharp edges. The representation of particle morphology is shown in Figure 2. With a larger number of particles, these merges into larger units. This reduces the risk of the particle being directly inhaled into the lungs [17].

The processes, protective equipment and exposure times used at individual workplaces are very different. Due to the very short exposure (only during the painting itself) and a number of protective equipment (general ventilation of the closed room, respirator, fresh air supply) in combination with relatively small concentrations of particles, paint shops are much safer than welding shops. Although there are central ventilation systems in welding shops, they are very often not sufficient for ventilation of complex hall spaces of machine shops. This can be observed at the minimum measured values, which reached 30,000 particles $/ \mathrm{cm}^{3}$. These values were measured before and after the shift when no processes were taking place. Here comes the problem with exposure: workers in welding shops are, apart from lunch breaks, constantly in the hall with a concentration of particles higher than the highest values in paint shops. Therefore, exposure times are much higher than for painters. Very low values were measured in the laboratory and the exposure time is also very low. The worker turns on the process and leaves the room. The worker returns to the room only after the completion of the process, when the values of particle concentrations are significantly reduced by ventilation. 


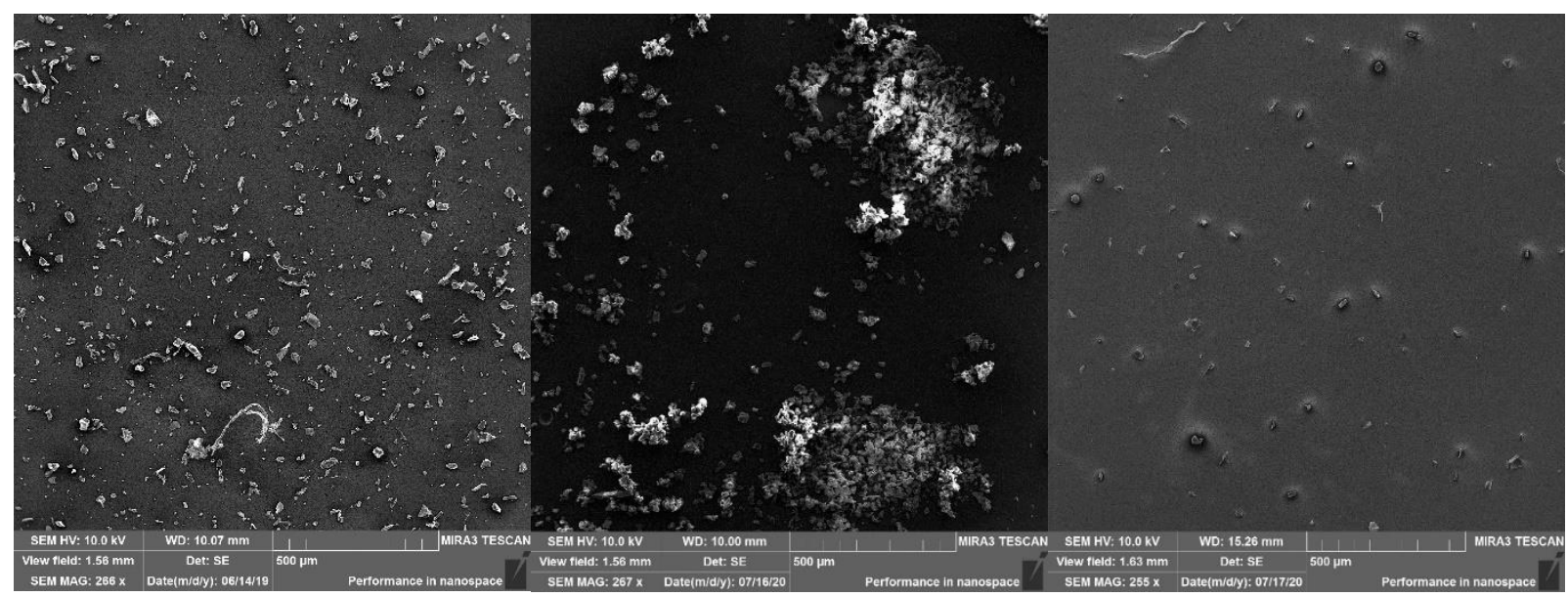

Figure 2 Example of SEM scan: left - welding shop; middle - paint shop; right - laboratory

In terms of evaluation work-related well-being should be considered: assessment and management of health risks, surveillance of employees' health; introduction of measures at workplace for the protection and promotion of workers health, contributing to wellbeing at work; and a special focus on workers fulfilment [18]. Workplace health and nanosafety questionnaire for workers is currently being constructed with regard to the legislation of the European Agency for Safety and Health at Work (OSHA). The aim of the questionnaire is to determine the level of knowledge and risks associated with nanoparticles, general knowledge of occupational safety and procedures, rights and obligations related to occupational safety and employee participation in safety issues. Despite the increasing use of nanotechnologies, employees who work with and are exposed to nanoparticles are often not educated in this area [19].

\section{CONCLUSION}

This study deals with exposure to fine and ultrafine particles in work environment. Their shape and composition depend on the examined process. The measured results of the concentration of particles in the air of the workplace show that, mainly particles with a size of about $0.3 \mu \mathrm{m}$ are produced. The shape of these particles on the filter is mainly irregular. In terms of elemental composition, the analysed particles contained mainly iron, manganese, silicon, organic materials and heavy metals. Nanoscale concentration of these elements, according to various studies, can have toxic effects. In comparison of samples from saliva and from respiratory tract we can see very similar exposure, so oral exposure should be tested as well.

\section{ACKNOWLEDGEMENTS}

\section{This paper is supported by TA ČR within the TL02000240 project of Increasing the Level of OSH Management in Workspace with Occurrence of Fine and Ultrafine particles.}

\section{REFERENCES}

[1] SCHULTE, P. A., GERACI, C. L., MURASHOV, V., et al. Occupational safety and health criteria for responsible development of nanotechnology. Journal of Nanoparticle Research. [online]. 2014, vol. 16, no. 1. Available from: https://doi.org/10.1007/s11051-013-2153-9. ISSN 1388-0764.

[2] VAN BROEKHUIZEN, P., VAN BROEKHUIZEN, F., CORNELISSEN, R., REIJNDERS, L. Workplace exposure to nanoparticles and the application of provisional nanoreference values in times of uncertain risks. Journal of Nanoparticle Research [online]. 2012, vol. 14, no.4. Available from: https://doi.org/10.1007/s11051-012-0770-3. ISSN 1388-0764. 
[3] BUNDSCHUH, M., FILSER, J., LÜDERWALD, S., et al. Nanoparticles in the environment: where do we come from, where do we go to? Environmental Sciences Europe. [online]. 2018, vol. 30, no. 1, p. 6. Available from: https://doi.org/10.1186/s12302-018-0132-6.

[4] PANDEY, R. K., PRAJAPATI, V. K. Molecular and immunological toxic effects of nanoparticles. International Journal of Biological Macromolecules. [online]. 2018, vol. 107, pp. 1278-1293. Available from: https://doi.org/10.1016/J.IJBIOMAC.2017.09.110.

[5] ROY, R., KUMAR, S., TRIPATHI, A., DAS, M., AND DWIVEDI, P. D. Interactive threats of nanoparticles to the biological system. Immunology Letters. [online]. 2014, vol. 158, no. 1-2, pp. 79-87. Available from: https://doi.org/10.1016/J.IMLET.2013.11.019.

[6] SUKHANOVA, A., BOZROVA, S., SOKOLOV, P., BERESTOVOY, M., KARAULOV, A., NABIEV, I. Dependence of nanoparticle toxicity on their physical and chemical properties. Nanoscale research letters. [online]. 2018, vol. 13.1, no. 44, pp. 1-21. Available from: https://doi.org/10.1186/s11671-018-2457-x.

[7] CONNELL, Des W., QIMING, J. Y., VERMA, V. Influence of exposure time on toxicity-An overview. Toxicology. [online]. 2016, vol. 355, pp. 49-53. Available from: https://doi.org/10.1016/..tox.2016.05.015.

[8] DE MATTEIS, V. Exposure to inorganic nanoparticles: routes of entry, immune response, biodistribution and in vitro/in vivo toxicity evaluation. Toxics. [online]. 2017, vol. 5, no. 4, p. 29. Available from: https://doi.org/10.3390/toxics5040029.

[9] SONG, Y., LI, X., DU, X. Exposure to nanoparticles is related to pleural effusion, pulmonary fibrosis and granuloma. European respiratory journal. [online]. 2009, vol. 34, no. 3, pp. 559-567. Available from: https://doi.org/10.1183/09031936.00178308.

[10] PONCE DEL CASTILLO, A. M. Nanomaterials And Workplace Health \& Safety. What Are The Issues For Workers?. European Trade Union Institute. [online]. 2013. [viewed 2020-09-29]. Available from: https://www.etui.org/sites/default/files/ez import/Guide Nanos EN.pdf

[11] European Agency for Safety and Health at Work. Managing nanomaterial in the workplace. [online]. Brussels, Belgium [viewed 2020-09-29]. Available from: https://osha.europa.eu/cs/themes/nanomaterials.

[12] Regulation (EC) No 1907/2006 of the European Parliament and of the Council of 18 December 2006 concerning the Registration, Evaluation, Authorisation and Restriction of Chemicals (REACH).

[13] VIITANEN, A.-K., UUKSULAINEN, S., KOIVISTO, A. J., HÄMERI, K., KAUPPINEN, T. Workplace Measurements of Ultrafine Particles-A Literature Review. Annals of Work Exposures and Health. [online]. 2017, vol. 61, no. 7, pp. 749-758. Available from: https://doi.org/10.1093/annweh/wxx049.

[14] NOWACK, B., BROUWER, C., GEERTSMA, R. E., HEUGENS, E. H. W., ROSS, B. L., TOUFEKTSIAN, M.-C., WIJNHOVEN, S. W. P., AITKEN, R. J. Analysis of the occupational, consumer and environmental exposure to engineered nanomaterials used in 10 technology sectors, Nanotoxicology. [online]. 2012, vol. 7, no. 6, pp. 11521156. Available from: https://doi.org/10.3109/17435390.2012.711863.

[15] DANNA, K.; GRIFFIN, R., W. Health and well-being in the workplace: A review and synthesis of the literature. Journal of management. [online]. 1999, vol. 25, no. 3, pp. 357-384. Available from: https://doi.org/10.1016/S0149-2063(99)00006-9.

[16] International Labour Organization: Workplace well-being [online]. Geneve, Switzerland [viewed 2020-09-29]. Available from: https://www.ilo.org/safework/areasofwork/workplace-health-promotion-and-wellbeing/WCMS 118396/lang--en/index.htm

[17] THOMAS, R. J. Particle size and pathogenicity in the respiratory tract. Virulence [online]. 2014, vol. 4, no. 8, pp. 847-858 [viewed 2020-07-13]. DOI: 10.4161/viru.27172. ISSN 2150-5594. Available from:

http://www.tandfonline.com/doi/abs/10.4161/viru.27172

[18] BUFFET, M., A., GERVAIS, R., L., LIDDLE, M., EECKELAERT, L. Well-being at work: creating a positive work environment. Publications Office of the European Union. [online]. 2013. ISSN: 1831-9351, 76, DOI:

10.2802/52064. Available from: https://osha.europa.eu/en/publications/well-being-work-creating-positive-workenvironment

[19] PONCE DEL CASTILLO, A. Training for workers and safety representatives on manufactured nanomaterials. NEW SOLUTIONS: A Journal of Environmental and Occupational Health Policy. [online]. 2019, vol. 29, no. 1, pp. 36-52. Available from: https://doi.org/10.1177/1048291119830085. 